\title{
COMPARATIVE STUDY ON THERAPEUTIC POTENTIAL OF CAFFEIC ACID AND SILYMARIN IN PARACETAMOL-INDUCED HEPATOTOXICITY: EFFECT ON HO-1, OXIDATIVE STRESS, HEPATIC INFLAMMATION AND NEUTROPHILS INFILTRATION
}

\author{
Mona F. El-Azab \\ Department of Pharmacology and Toxicology, Faculty of Pharmacy, Suez Canal University, Ismailia \\ 41522, Egypt
}

\begin{abstract}
Paracetamol is a widely used analgesic and antipyretic drug, but at high doses it leads to undesirable side effects, mainly hepatotoxicity. The hepatoprotective effect of caffeic acid has been previously reported, however the mechanism of this protective effect is not fully explored. The current study aimed to investigate the therapeutic potential of caffeic acid vs. silymarin in paracetamol-induced hepatic damage. To better understand the mechanisms by which these phenolic compounds confer their protective effects, parameters of lipid peroxidation, hepatic inflammation and neutrophils infiltration were evaluated. In addition, liver toxicity markers and hepatic antioxidants (enzymatic as well as non-enzymatic) were measured.

Daily administration of paracetamol $(700 \mathrm{mg} / \mathrm{kg}$, p.o.) caused hepatic injury that was manifested as increased hepatic levels of malonaldehyde (MDA), tumor necrosis factor-alpha (TNF- $\alpha$ ) and heme oxygenase (HO-1) with marked increase in myeloperoxidase (MPO) activity, depletion of liver reduced glutathione, and diminished catalase and super-oxide dismutase (SOD) activities. Furthermore, serum liver enzymes (ALT, AST, GGT) were significantly increased along with hepatocellular degeneration and steatosis. Co-treatment with caffeic acid or silymarin alleviated paracetamol-induced oxidative stress, blunted TNF- $\alpha$ levels and MPO activity, while enhanced HO-1 levels with restoration of antioxidant enzymes activities. This was accompanied by normalization of liver transaminases and improvement of hepatic architecture. Interestingly, the effect of caffeic acid on $\mathrm{HO}-1, \mathrm{TNF}-\alpha$, and MPO was more prominent when compared to silymarin.

The present study provide an evidence on the multiple mechanisms by which caffeic acid as well as silymarin grant their hepatoprotective activities mainly through the induction of HO-1 in addition to the reduction of oxidative stress burden in hepatocytes. The powerful anti-oxidant effect was accompanied by a significant anti-inflammatory activity.
\end{abstract}

Keywords: caffeic acid, heme oxygenase-1, hepatotoxicity, oxidative stress, paracetamol, silymarin

\section{INTRODUCTION}

Paracetamol is a commonly used analgesic and antipyretic agent which is usually safe and well tolerated when used at therapeutic doses. However, acute paracetamol overdose causes severe and fatal hepatotoxicity (Maddrey, 2005). Paracetamol toxicity is one of the most common causes of poisoning worldwide, mainly causing liver injury and acute liver failure (Larson et al., 2005; Ryder and Beckingham, 2001). Damage to the liver results from one of 
paracetamol metabolites, that is N-acetyl-p-benzoquinoneimine (NAPQI). NAPQI is a highly reactive intermediate that depletes hepatic glutathione and binds covalently to intracellular proteins including mitochondrial proteins (James et al., 2003). Consequently, enormous hepatocellular necrosis occurs as a result of mitochondrial dysfunction, oxidative and nitrative stress, and inflammatory reactions (Jaeschke and Bajt, 2006).

Several studies have documented the effective protection afforded by antioxidants and anti-inflammatory agents against paracetamol-induced hepatotoxicity (Girish $\boldsymbol{e t}$ al., 2009; Nagi et al., 2010; Yan et al., 2009). However most of these studies reported the protective effect of various agents only when administered prior to paracetamol insult. Hence, there is a need to find agents that can stop or even reverse the hepatotoxicity when administered following paracetamol-induced injury.

Caffeic acid and silymarin are phenolic compounds widely present in plant kingdom (Duke, 1992). Caffeic acid has been reported to posses many pharmacological activities including anti-inflammatory (Moreira et al., 2000), anti-tumor (Soleas et al., 2002), anti-allergic (Kimata et al., 2000), anti-ulcer (Al-Sereiti et al., 1999), cardioprotective (Cornicelli and Trivedi, 1999) and immunomodulatory (Russo et $\boldsymbol{a l}$., 1999) activities. Likewise, silymarin was reported to exhibit several biological activities including antioxidant action (Lieber, 2004), chemopreventive (Chlopcikova et al., 2004), and immunomodulatory effects (Schumann et al., 2003; Yoo et al., 2004) in addition to its well established hepatoprotective activity (Berger and Kowdley, 2003; Lieber et al., 2003). Although the beneficial effect of caffeic acid in models of chemically-induced hepatic injury has been previously reported (Janbaz et al., 2004), the mechanism of its hepatoprotective effect needs further investigation.

The main objectives of the current study were to evaluate the protective effects of caffeic acid concomitant treatment in comparison with silymarin against paracetamol-induced hepatic injury in rats and to investigate the possible mechanism(s) underlying these effects. Therapeutic potential was assessed by monitoring liver injury through estimation of serum alanine aminotransferase (sALT), aspartate aminotransferase (sAST), and gamma-glutamyl transferase (GGT) as well as hepatic lipid peroxidation expressed as malondialdehyde (MDA). In addition, the activities of hepatic endogenous antioxidants including reduced glutathione (GSH), catalase, and superoxide dismutase (SOD), hepatic levels of the pro-inflammatory marker TNF- $\alpha$, and the neutrophils infiltration marker myeloperoxidase (MPO) were evaluated.

\section{MATERIALS AND METHODS:}

\subsection{Drugs, kits, and chemicals}

Caffeic acid was purchased from sigma (St. Louis, MO, USA). Paracetamol and Silymarin were provided by Egyptian Int. Pharmaceutical Industries Co. and Pharaonia Pharmaceuticals Co., respectively. Kits for alanine aminotransferase (ALT, or sGPT), aspartate aminotransferase (AST, or sGOT), and gamma-glutamyl transferase (GGT) were purchased from (bioMérieux, France). Commercially available kits (Bio-Diagnostic, Egypt) were used for determining the enzymes superoxide-dismutase (SOD) and catalase, reduced glutathione (GSH), and the lipid-peroxide marker malondialdehyde (MDA). Liver heme oxygenase (HO-1) levels were determined using Rat HO-1 Enzyme Linked Immunosorbent Assay (ELISA) Kit (Stressgens, MI,USA). Rat tumor necrosis factor-alpha (TNF- $\alpha$ ) Immunoassay Kit [Quantikine, ELISA] was purchased from R\&D systems (Minneapolis, USA) and myeloperoxidase kit was 
purchased from Northwest Co. (Canada). All other chemicals were obtained from Sigma (St. Louis, MO, USA) unless otherwise mentioned.

\subsection{Animals}

Male Wister rats weighing 120-150g were obtained from the Egyptian Organization for Biological Products and Vaccines (Egypt) and housed under controlled temperature $\left(25 \pm 1^{\circ} \mathrm{C}\right)$ on a $12 \mathrm{~h}$ light/dark cycle. Rats were allowed to acclimatize for one week before starting the experiment. Food and water were allowed ad libitum during the study period.

\subsection{Experimental design} follows:

Thirty two rats were randomly divided into four groups of eight rats each and treated as

- $1^{\text {st }}$ group: rats that served as the untreated (normal) control and were administered single daily dose of $5 \mathrm{ml} / \mathrm{kg}$ body weight of distilled water orally for 14 days.

- $\quad 2^{\text {nd }}$ group: rats that served as the model control and were administered single daily dose of paracetamol suspension at $700 \mathrm{mg} / \mathrm{kg}$ body weight for 14 days.

- $\quad 3^{\text {rd }}$ group: rats were co-treated daily with single oral dose of caffeic acid at $40 \mathrm{mg} / \mathrm{kg}$ body weight 1 hour after oral administration of paracetamol suspension $(700 \mathrm{mg} / \mathrm{kg}$ ) for 14 days.

- $4^{\text {th }}$ group: rats were co-treated daily with single oral dose of silymarin at $100 \mathrm{mg} / \mathrm{kg} 1$ hour after oral administration of paracetamol suspension $(700 \mathrm{mg} / \mathrm{kg}$ ) for 14 days.

\subsection{Sample preparation}

At the end of experiment, 6 rats from each group were selected randomly and sacrificed by cervical dislocation, blood samples were collected, left for $60 \mathrm{~min}$ to clot, and then centrifuged for $10 \mathrm{~min}$ at $5000 \mathrm{rpm}$ to obtain clear sera which were stored at $-20^{\circ} \mathrm{C}$.

The livers were excised, divided into two portions, one portion was washed with ice-cold saline, and subsequently homogenized in cold potassium phosphate buffer $(0.05 \mathrm{M}, \mathrm{pH} 7.4)$. The homogenates were centrifuged at $14000 \mathrm{rpm}$ for $15 \mathrm{~min}$ at $4^{\circ} \mathrm{C}$ and the resulting supernatant was stored at $-80^{\circ} \mathrm{C}$. The other portion was kept for histopathological evaluation.

\subsection{Biochemical determination of liver enzymes}

Liver enzymes (ALT, AST, and GGT) were determined in serum samples spectrophotometrically using appropriate kits. Protocols used were according to the recommended manufacturer procedures.

\subsection{Measurements of lipid peroxidation and antioxidants in liver}

Liver homogenate from different groups were used for measuring MDA, GSH, and the activities of SOD and catalase using standard spectrophotometric assays. Levels of MDA as thiobarbituric acid-reactive substances (TBRS) were measured by the method of Ohkawa et al. (1979). GSH was determined based on the use of Ellman's reagent (Beutler et al., 1963). SOD and catalase activities were measured as described previously (Aebi, 1984; Nishikimi et al., 1972). 


\subsection{Determination of liver TNF- $\alpha$}

Levels of TNF- $\alpha$ in liver homogenate were determined using ELISA following the manufacturer's protocol (R\&D systems). In brief, to a 96-well microplate pre-coated with polyclonal antibody specific for rat TNF- $\alpha, 50 \mu \mathrm{l}$ assay diluent and $50 \mu \mathrm{l}$ samples were added. Recombinant rat TNF- $\alpha$ was used to set up the corresponding standard curve. After incubation for $2 \mathrm{~h}$ at room temperature, the wells were washed and polyclonal anti-rat TNF- $\alpha$ antibody conjugated to horseradish peroxidase was added. Incubation was continued for $2 \mathrm{~h}$, plates were washed; substrate solution was added to each well and incubated for $30 \mathrm{~min}$. The enzyme reaction yielded a blue product that turned yellow when the stop solution was added. The O.D at 450nm (correction wavelength set at $570 \mathrm{~nm}$ ) was measured using microplate reader (Metertech, M960).

\subsection{Determination of liver HO-1}

Levels of HO-1 in liver homogenate were determined using ELISA following the manufacturer's protocol (Stressgen). Briefly, to a 96-wellmicroplate pre-coated with monoclonal antibody specific for rat HO-1, $100 \mathrm{ml}$ standards, sample diluent, or samples were added to appropriate wells. Recombinant rat HO-1was used to setup the standard curve. After incubation for $1 \mathrm{~h}$ at room temperature, the wells were washed and polyclonal antibody specific for rat HO-1 was added followed by incubation for another $1 \mathrm{~h}$. After washing, $100 \mathrm{ml}$ of rat HO-1 horseradish peroxidase conjugate was added. Incubation was continued for 30min at room temperature, plates were washed; tetramethylbenzidine substrate solution was added to each well and incubated for $15 \mathrm{~min}$ in dark. The enzyme reaction yielded a blue product that turned yellow when the stop solution was added. The O.D at 450nm was measured using microplate reader (Metertech, M960).

\subsection{Determination of MPO activity in liver}

Myeloperoxidase (MPO) activity was determined as described by Weiss and coworkers (1982). Briefly, hypochlorous acid (HOCl) was formed from MPO catalyzed reaction between chloride and hydrogen peroxide. $\mathrm{HOCl}$ was rapidly trapped by amino acid taurine to form a stable oxidant taurine chloramine. After incubation for 30min, the MPO catalyzed reaction was stopped by adding catalase to eliminate hydrogen peroxide. Taurine chloramine was then allowed to react with the chromophore 5-thio-2-nitrobenzoic acid (TNB) to give a colorless reaction product 5-5-dithiobis(2-nitrobenzoic acid) or DTNB. By following the decrease in absorbance at $412 \mathrm{~nm}$, MPO activity was measured. One unit is the amount of MPO that can produce 1.0 nmole of taurine chloramine (hypochlorous acid) at $\mathrm{pH} 6.5$ and $25^{\circ} \mathrm{C}$ during 30 minutes in the presence of $100 \mathrm{mM}$ chloride and $100 \mu \mathrm{M}$ of hydrogen peroxide.

\subsection{Histopathological examination of liver tissue}

The other liver portion from each animal was fixed in $10 \%$ formalin, dehydrated in ascending grades of alcohol and embedded in paraffin. Sections were cut at $4 \mu \mathrm{m}$, stained with hematoxylin and eosin $(\mathrm{H} \& \mathrm{E})$ and examined under a light microscope for histopathologic evaluations.

\subsection{Statistical analysis}

All data were expressed as mean \pm S.E.M. Statistical significance was tested by one way analysis of variance (ANOVA) followed by Bonferroni post hoc analysis. A P value $<0.05$ was considered statistically significant. 


\section{RESULTS}

\subsection{Effect of caffeic acid vs. silymarin on hepatic toxicity markers}

Treatment with paracetamol $(700 \mathrm{mg} / \mathrm{kg}$, daily) for 2 weeks disrupted liver function as reflected by marked (2- to 6-fold) rises in serum alanine aminotransferase (Pestka et al., 2004), aspartate aminotransferase (Camacho-Barquero et al., 2007), and gamma-glutamyl transferase (GGT) (Fig. 1). The treatment with caffeic acid concomitantly with paracetamol significantly ( $P$ $\leq 0.05)$ inhibited paracetamol-induced increases in serum aminotransferases and kept their levels close to normal values. The effect of silymarin, the known hepatoprotective agent, on ALT and AST was comparable to caffeic acid. However, the level of GGT after silymarin treatment stayed slightly higher than normal levels.

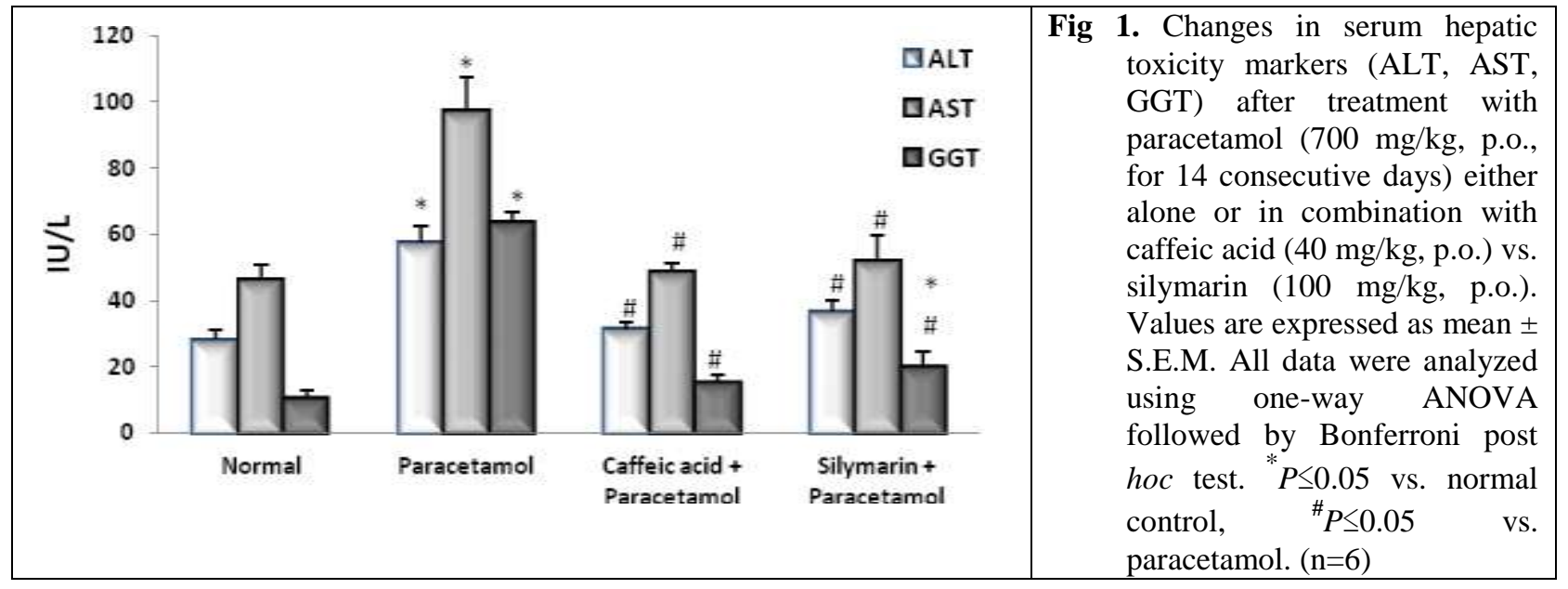

\subsection{Effect of caffeic acid vs. silymarin on lipid peroxidation and antioxidants in liver}

Oxidative stress and endogenous antioxidant levels were evaluated to gain insights into the hepatic molecular and cellular changes occurring following paracetamol treatment. Fig 2A demonstrates that paracetamol resulted in 4-fold increase in MDA levels in liver cell homogenates indicating lipid peroxidation. This was accompanied by $63 \%$ reduction in GSH levels (Fig 2B). In addition, the activities of antioxidant enzymes, catalase and SOD, were depleted in liver following paracetamol treatment as evident by $69 \%$ and $47 \%$ reduction, respectively (Fig 2C-D). Treatment with caffeic acid or silymarin significantly $(P \leq 0.05)$ suppressed hepatic lipid peroxidation and prevented the reductions of GSH level and catalase as well as SOD activities resulting from paracetamol administration. 


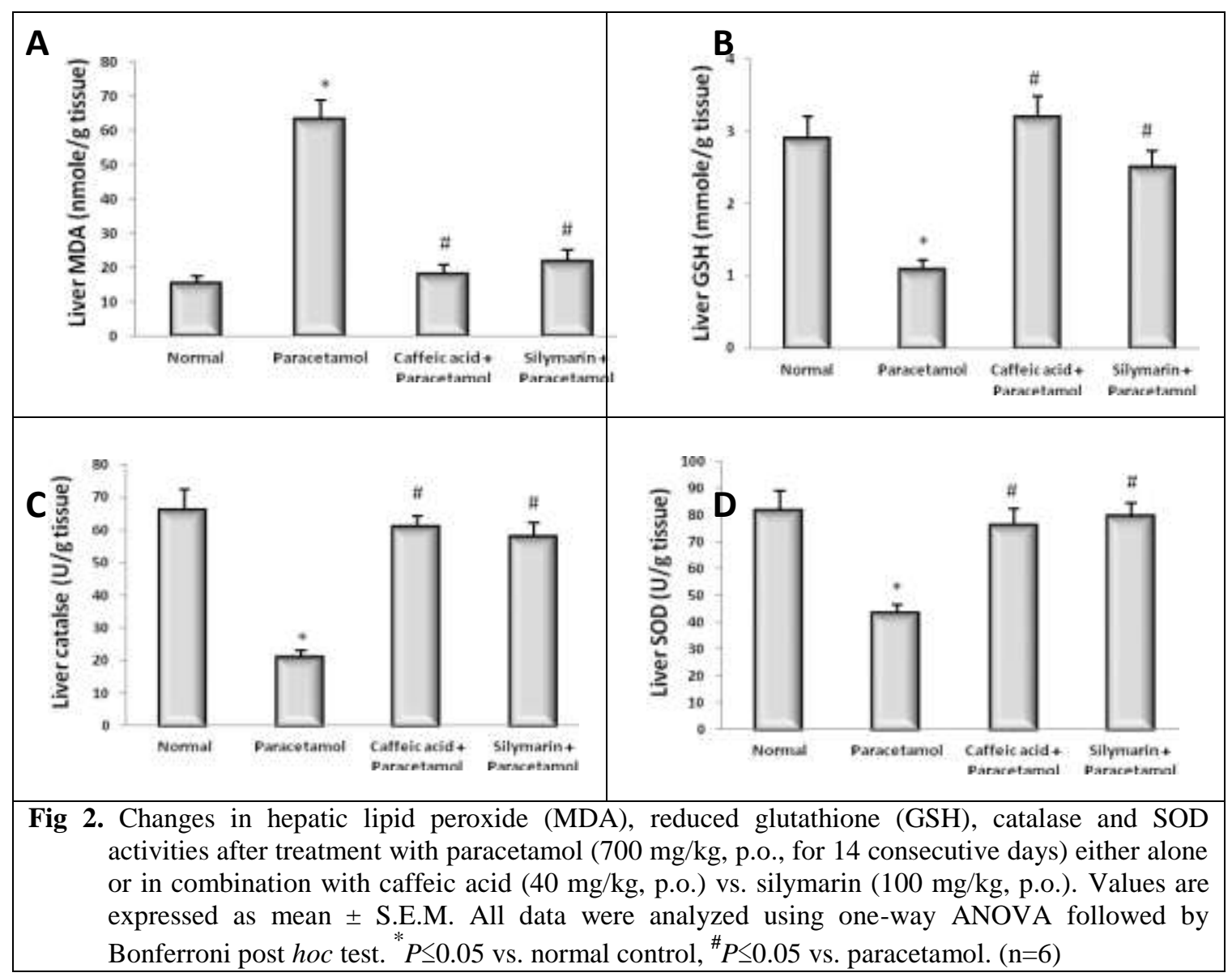

\subsection{Effect of caffeic acid vs. silymarin on HO-1 levels in liver}

Following treatment with paracetamol for 2 weeks, a marked (15-fold) increase in heme oxygenase-1 (HO-1) protein was observed in liver cell homogenate suggesting a stress response by hepatocytes. The co-treatment with caffeic acid resulted in a further 5-fold increase in HO-1 expression while the concomitant treatment with silymarin caused only 3.5-fold increase in HO1 compared to paracetamol treated group (Fig. 3).

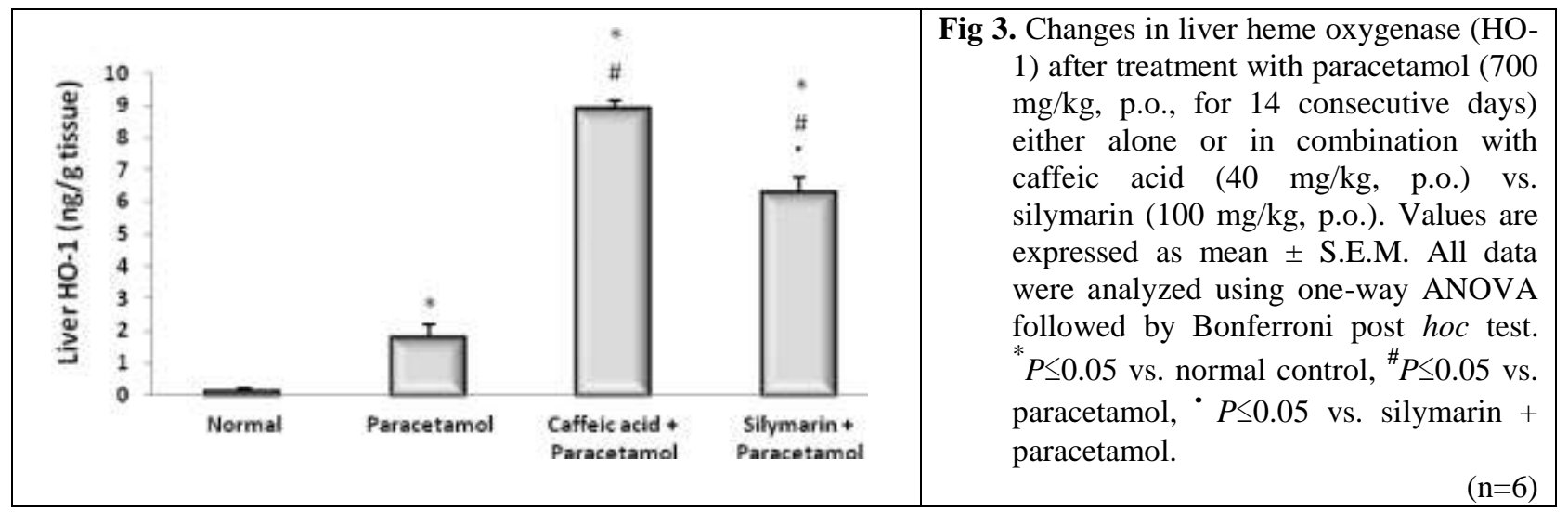




\subsection{Effect of caffeic acid vs. silymarin on paracetamol-induced hepatic inflammation}

To gain more insights into the mechanisms by which caffeic acid and/or silymarin confer their hepatoprotective effects against paracetamol-induced hepatotoxicity, TNF- $\alpha$ and MPO were evaluated as markers for hepatic inflammation and neutrophils infiltration, respectively. Paracetamol significantly $(P \leq 0.05)$ increased the hepatic TNF- $\alpha$ level (3.6-fold) compared with control rats. Caffeic acid or silymarin co-administration with paracetamol significantly $(P \leq$ 0.05 ) reduced paracetamol-induced hepatocytic production of TNF- $\alpha$ by $66 \%$ and $50 \%$, respectively (Fig. 4A). Similarly, paracetamol markedly (7-fold) increased MPO activity in liver homogenate compared with normal control group. Co-administration of caffeic acid or silymarin significantly $(P \leq 0.05)$ reduced paracetamol-induced MPO activity in liver cell homogenates by $78 \%$ and $68 \%$, respectively, compared with paracetamol control group (Fig. 4B).

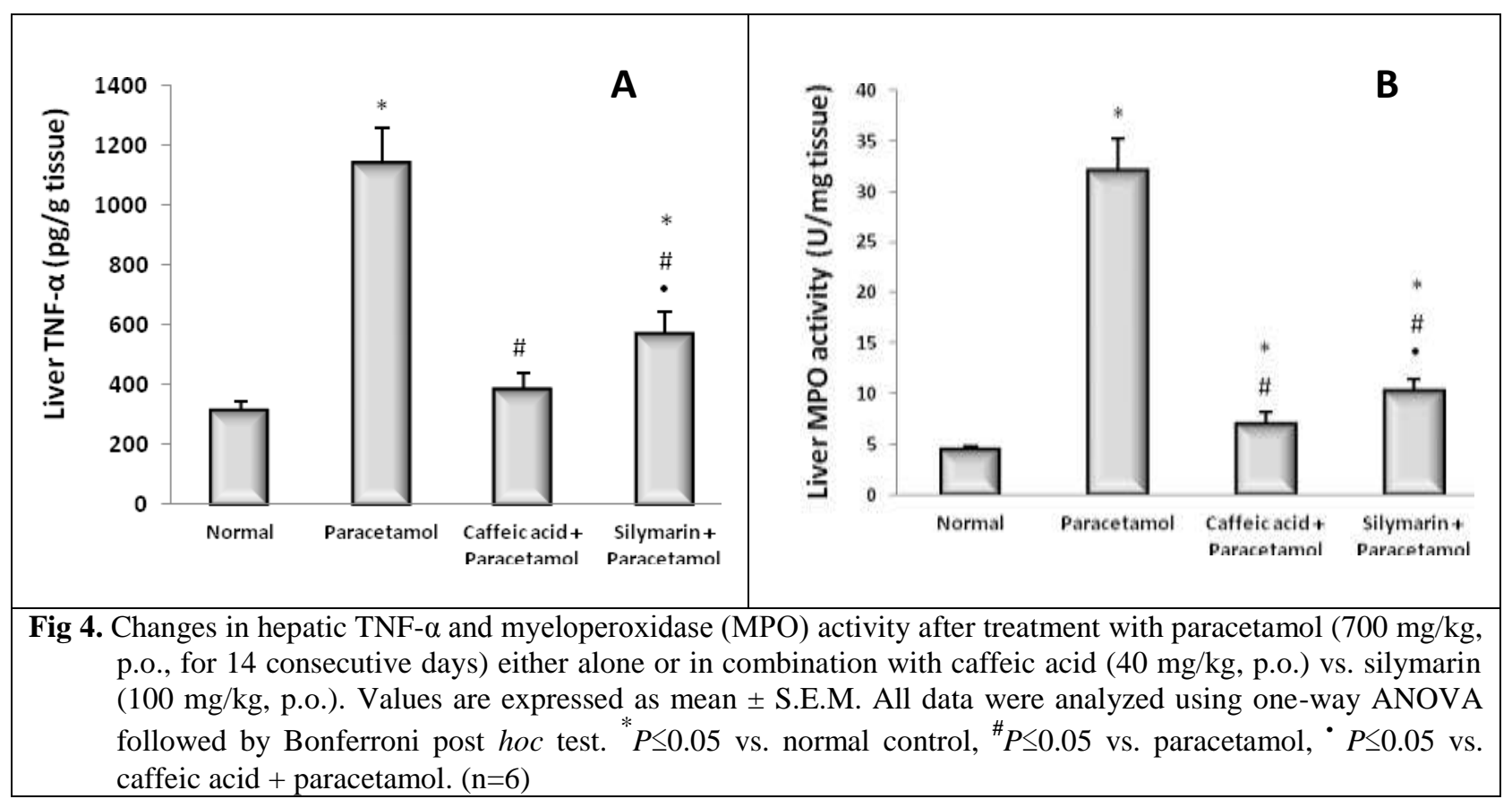

\subsection{Histopathological evaluation}

The microscopic examination of liver of control rats showed normal architecture without any signs of vascular or inflammatory changes (Fig. 2A). Histopathological examination revealed that paracetamol induced diffuse cytoplasmic vacuolation, centrilobular necrosis, vascular congestion and nuclear pyknosis of the hepatocytes which are indicative of acute hepatocellular injury (Fig. 2B) that came in line with the increased levels of serum aminotranferases. Whereas, caffeic acid or silymarin co-treatment preserved the liver histology close to the normal architecture with minimal small focal necrosis and no evidence of degeneration or steatosis (Fig. 2C-D) which is consistent with the amelioration of pathologic anomalies by both compounds. 


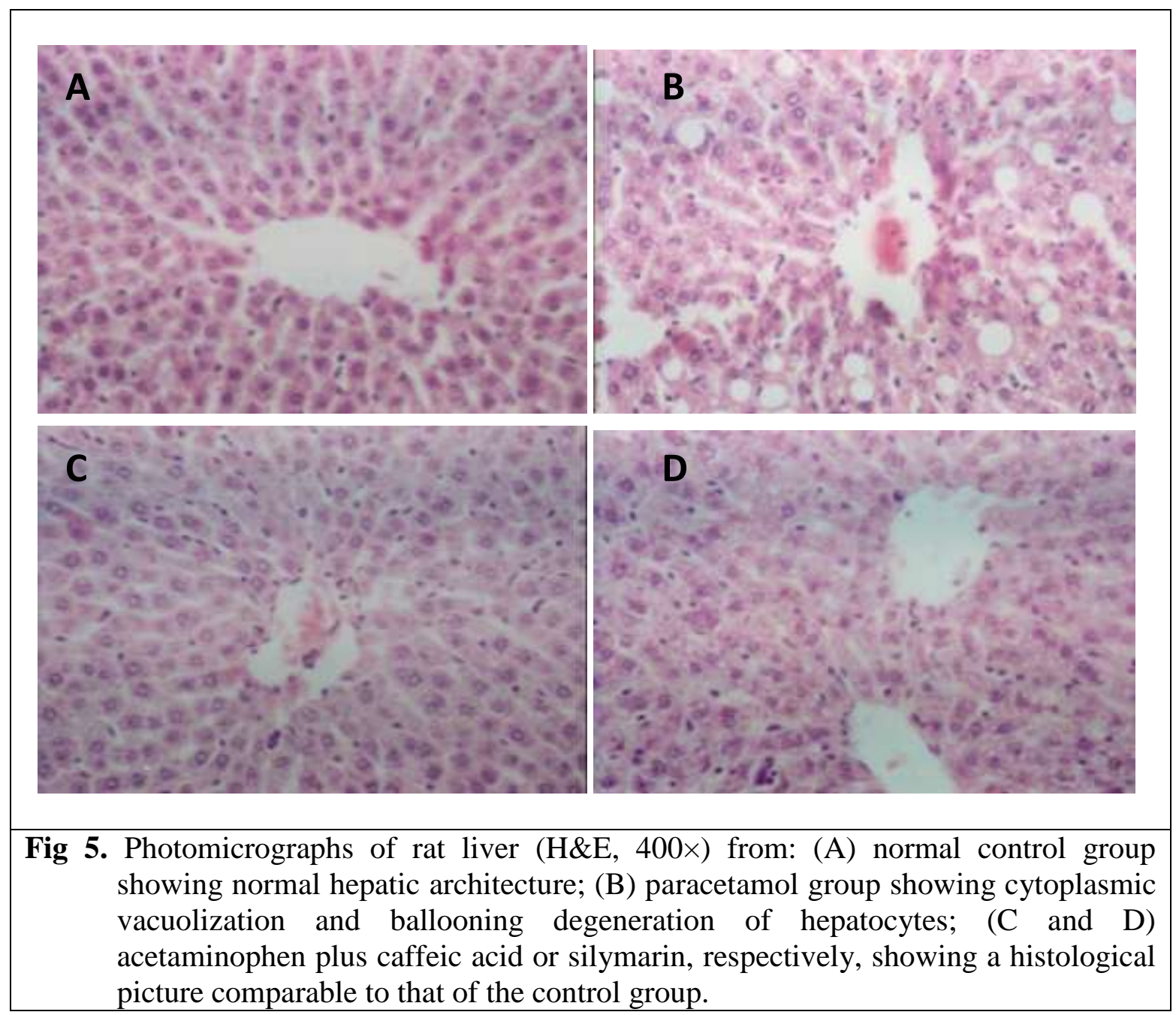

\section{DISCUSSION}

Caffeic acid, one of the most widely distributed flavonoids, has been demonstrated to have potent antioxidant ability (Jayanthi and Subash, 2010; Rice-Evans and Miller, 1996) and has been reported to protect cells from oxidative damages caused by a diverse range of oxidative stresses, including paracetamol-mediated toxicity (Janbaz et al., 2004). However, to the best of our knowledge, the present study is the first to investigate the therapeutic potential of "posttreatment" with caffeic acid against paracetamol-induced hepatotoxicity in rats.

Cancer patients on chemotherapy generally receive higher doses of paracetamol to relieve pain (Nassar et al., 2009). Hepatic damage as a result of paracetamol overdoses in human is fairly common (Nelson, 1995). At therapeutic doses, paracetamol is metabolized primarily in the liver via glucuronidation and sulfation reactions, and results in water-soluble metabolites that are excreted via kidney. As a result of the metabolic conversion of paracetamol by the microsomal CYP-450 enzyme system, a highly reactive intermediate, N-acetyl-p-benzoquinoneimine (NAPQI) is produced (Mitchell $\boldsymbol{e t}$ al., 1973). NAPQI directly reacts with GSH and at overdoses of paracetamol, depletion of cellular GSH occurs allowing NAPQI to bind to cellular proteins especially in the mitochondria. The resulting mitochondrial oxidative and nitrative stress leads to mitochondrial dysfunction and eventually hepatocellular necrosis (Jaeschke et al., 2011). 
Indeed, histopathological evaluation confirmed the hepatic damage associated with high doses of paracetamol in the current model as was evident by hepatic necrosis and steatosis. In addition, the elevated levels of serum transaminases observed in this study support the previous observation. Our results are in accordance with previous reports showing that hepatic damage resulting from paracetamol overdoses is always associated with increased serum liver enzymes as marker for hepatotoxicity (Heard, 2008; Larson et al., 2005)

Paracetamol also induces the release of numerous cytokines and signaling molecules from activated Kupffer cells, including TNF- $\alpha$ which in turn up-regulates the iNOS enzyme (Gardner et al., 2002; Morris and Billiar, 1994) resulting in increased hepatic production of nitric oxide (Jaeschke et al., 2011). Excess nitric oxide depletes intracellular GSH that increases the susceptibility to oxidative stress (Clancy and Abramson, 1995). Moreover, excess nitric oxide reacts with superoxide anion to generate peroxynitrite radical that causes further cell damage by oxidizing and nitrating cellular macromolecules. In agreement with previous studies (Girish et al., 2009; Nagi et al., 2010; Oz and Chen, 2008; Yan et al., 2009), current results demonstrated that oxidative stress accompanied by increased lipid peroxidation, undermined antioxidant defenses and increased release of pro-inflammatory cytokines which are the hallmarks of paracetamol hepatotoxicity. The antioxidant effect of caffeic acid was evident in the this study through the restoration of catalase and SOD activities as well as GSH with blunting of lipid peroxidation. Our results came in line with previous reports that demonstrated similar effect of caffeic acid in different models (Jayanthi and Subash, 2010; Kus et al., 2004). Silymarin produced a comparable effect to caffeic acid in the current study. The antioxidant activities of both polyphenols were associated with an improved liver architecture and normalized serum transaminases.

There is an emerging evidence that caffeic acid, as well as other polyphenols, may exert modulatory actions on the endogenous antioxidative defense system by interactions with intracellular signaling cascades in addition to their ability of quenching ROS (Williams $\boldsymbol{e t} \boldsymbol{a l}$., 2004). Heme oxygenase-1 (HO-1), a redox-sensitive inducible protein that provides efficient cytoprotection against oxidative stress, has attracted much attention for its up-regulation in a variety of stress-related circumstances (Dore, 2002; Ryter et al., 2007). Growing evidences indicate that HO-1 plays a key role in defense mechanisms against oxidative damages (Nakahira et al., 2003; Ryter et al., 2007). The induction of the HO-1 gene has been proposed to be a beneficial adaptive response to oxidative stress (Applegate et al., 1991). Further, Alum et al. (1995) have shown HO-1 gene to be induced by reactive oxygen species. It is known that both biliverdin and bilirubin, the byproducts of heme metabolism by HO-1, exhibit antioxidant properties. In the light of these observations, our findings suggest that the reactive oxygen species released from the damaged liver as a result of paracetamol overdose induced HO-1 expression. Indeed, activation of HO-1 at the transcriptional level has been previously reported in acetaminophen-induced hepatitis which confirm the current finding (Bauer et al., 2000; Ishida et al., 2006). On the other hand, preceding findings showed that caffeic acid markedly increased heme oxygenase activity and HO-1 protein in astrocytes (Scapagnini et al., 2002). Similarly, silymarin was reported to up-regulate HO-1 mRNA in human hepatoma cells (Bonifaz et al., 2009). However, as far as we know, the current study is the first to investigate the effect of caffeic acid and silymarin on liver HO-1 in the paracetamol-induced hepatotoxicity. Both caffeic acid and silymarin enhanced the production of HO-1 by the liver far beyond the effect of paracetamol alone suggesting an additional mechanism by which these polyphenols confer a protective effect against paracetamol-induced toxicity. 
TNF- $\alpha$ is a pro-inflammatory cytokine that is associated with liver injury in many experimental models (Camacho-Barquero et al., 2007; Cover et al., 2006) and human diseases (Felver et al., 1990). In the current study, treatment of rats with paracetamol resulted in a 3.6fold increase in hepatic TNF- $\alpha$. Previous reports showed that paracetamol-induced liver injury resulted in a significant increase in TNF- $\alpha$ which is in accordance with our results (Cover $\boldsymbol{e t}$ al., 2006; Sener et al., 2006; Teng et al., 2012). However, the treatment of paracetamol-intoxicated rats with caffeic acid or silymarin significantly inhibited the rise in TNF- $\alpha$ indicating antiinflammatory activity of the currently studied polyphenols. Preceding studies showed the inhibitory effect of caffeic acid or silymarin on TNF- $\alpha$ expression in different models support our finding (Chao et al., 2010; Song et al., 2006).

It is well established that free radicals play a role in the recruitment of neutrophils by injured tissues as a potential source of free radicals and activating cytotoxic enzymes, namely MPO (Lau et al., 2005), which in turn maintain the vicious cycle of generating more free radicals resulting in lipid peroxidation. The infiltration of polymorphnuclear leukocytes that generates oxygen radicals and induces direct tissue injury has been previously reported with indomethacin treatment (Tanaka et al., 2001). This effect can result in increased lipid peroxidation that may exacerbate the already existing damage. In the present study, the elevated hepatic MDA concentrations along with increased hepatic MPO activity following paracetamol intoxication indicated the contribution of neutrophils infiltration and the impact of free radical generation on oxidative hepatic damage. While the co-treatment with caffeic acid or silymarin abrogated hepatic neutrophils infiltration as was evident by the significant reduction in MPO activity. This was consistent with our histopathological findings that showed normal architecture in the liver tissues from caffeic acid- or silymarin-treated animals and this could be attributed to the known antioxidant and anti-inflammatory activities of both compounds (Jayanthi and Subash, 2010; Lieber, 2004; Muriel, 2009).

It is noteworthy that the HO system abates inflammation through several mechanisms including the suppression of macrophage-infiltration and abrogation of oxidative/inflammatory transcription factors like NF- $\kappa \mathrm{B}$, JNK and activating protein-1 (Ndisang, 2010). HO-1 is stimulated by a wide variety of different stimuli including oxidative and inflammatory insults (Jonas et al., 2003; Mohri et al., 2006), hyperglycemia (Jonas et al., 2003), hypertension (Ndisang et al., 2003), and dyslipidaemia (Landar et al., 2006). Therefore, HO-1 may be considered a sensitive index that is triggered in the onset of pathophysiological changes. However, in most cases the pathophysiological activation of HO-1 results only in a transient or marginal increase of HO-1 that falls below the threshold necessary to activate the downstream signaling components of the HO system (Ndisang et al., 2004; Ndisang et al., 2003) through which the HO system elicits its effects of restoring tissue homeostasis (Farombi and Surh, 2006; Ndisang et al., 2003). Therefore, a more vigorous enhancement of HO-1 would be needed to surmount that threshold, an effect that could be achieved by pharmacological agents capable of inducing HO (Ndisang and Jadhav, 2009). This may explain the results observed in the current study that although hepatic level of HO-1 was induced after paracetamol insult, it wasn't sufficient to subside the inflammatory response elicited by paracetamol reactive metabolites. On the other hand, the co-administration of caffeic acid or silymarin in this study abrogated the paracetamol-induced inflammation and neutrophils infiltration as was evident by significant reduction of hepatic TNF- $\alpha$ levels and MPO activities through the robust enhancement of hepatic HO-1levels and subsequent resume of liver homeostasis. 


\section{CONCLUSION}

The current study lends an additional evidence to paracetamol-induced hepatotoxicity which was manifested as increased serum liver enzymes and histopathological anomalies. The hepatotoxic effect involved disturbed antioxidant defense along with marked inflammation. Caffeic acid as well as silymarin treatment significantly ameliorated the liver injury induced by paracetamol overdoses in rats through multiple mechanisms including the restoration of antioxidant machinery, up-regulation of HO-1, and abrogation of inflammation and neutrophils infiltration. These data reinforce the concept of using natural agents with therapeutic potential for the protection against drug-induced hepatotoxicity.

\section{ACKNOWLEDGMENTS}

The authors thank Dr. Hend M. Tag, Assistant Professor of Physiology, Faculty of Science, Suez Canal University, Ismailia, Egypt, for her valuable help in the histopathological examination.

\section{REFERENCES}

Aebi, H., (1984): Catalase in vitro. Methods Enzymol 105, 121-126. PMID:6727660.

al-Sereiti, M.R., Abu-Amer, K.M., Sen, P., (1999): Pharmacology of rosemary (Rosmarinus officinalis Linn.) and its therapeutic potentials. Indian J Exp Biol 37, 124-130. PMID:10641130.

Alam, J., Camhi, S., Choi, A.M., (1995): Identification of a second region upstream of the mouse heme oxygenase-1 gene that functions as a basal level and inducer-dependent transcription enhancer. J Biol Chem 270, 11977-11984. PMID:7538129.

Applegate, L.A., Luscher, P., Tyrrell, R.M., (1991): Induction of heme oxygenase: a general response to oxidant stress in cultured mammalian cells. Cancer Res 51, 974-978. PMID: 1988141.

Bauer, I., Vollmar, B., Jaeschke, H., Rensing, H., Kraemer, T., Larsen, R., Bauer, M., (2000): Transcriptional activation of heme oxygenase-1 and its functional significance in acetaminophen-induced hepatitis and hepatocellular injury in the rat. J Hepatol 33, 395-406. PMID:11019995.

Berger, J., Kowdley, K.V., (2003): Is silymarin hepatoprotective in alcoholic liver disease? J Clin Gastroenterol 37, 278-279. PMID:14506381.

Beutler, E., Duron, O., Kelly, B.M., (1963): Improved method for the determination of blood glutathione. J Lab Clin Med 61, 882-888. PMID:13967893.

Bonifaz, V., Shan, Y., Lambrecht, R.W., Donohue, S.E., Moschenross, D., Bonkovsky, H.L., (2009): Effects of silymarin on hepatitis $C$ virus and haem oxygenase-1 gene expression in human hepatoma cells. Liver Int 29, 366-373. PMID: 18694403.

Camacho-Barquero, L., Villegas, I., Sanchez-Calvo, J.M., Talero, E., Sanchez-Fidalgo, S., Motilva, V., Alarcon de la Lastra, C., (2007): Curcumin, a Curcuma longa constituent, acts on MAPK p38 pathway modulating COX-2 and iNOS expression in chronic experimental colitis. Int Immunopharmacol 7, 333-342. PMID:17276891. 
Chao, C.Y., Mong, M.C., Chan, K.C., Yin, M.C., (2010): Anti-glycative and anti-inflammatory effects of caffeic acid and ellagic acid in kidney of diabetic mice. Mol Nutr Food Res 54, 388-395. PMID:19885845.

Chlopcikova, S., Psotova, J., Miketova, P., Simanek, V., (2004): Chemoprotective effect of plant phenolics against anthracycline-induced toxicity on rat cardiomyocytes. Part I. Silymarin and its flavonolignans. Phytother Res 18, 107-110. PMID:15022159.

Clancy, R.M., Abramson, S.B., (1995): Nitric oxide: a novel mediator of inflammation. Proc Soc Exp Biol Med 210, 93-101. PMID:7568290.

Cornicelli, J.A., Trivedi, B.K., (1999): 15-Lipoxygenase and its inhibition: a novel therapeutic target for vascular disease. Curr Pharm Des 5, 11-20. PMID:10066881.

Cover, C., Liu, J., Farhood, A., Malle, E., Waalkes, M.P., Bajt, M.L., Jaeschke, H., (2006): Pathophysiological role of the acute inflammatory response during acetaminophen hepatotoxicity. Toxicol Appl Pharmacol 216, 98-107. PMID:16781746.

Dore, S., (2002): Decreased activity of the antioxidant heme oxygenase enzyme: implications in ischemia and in Alzheimer's disease. Free Radic Biol Med 32, 1276-1282. PMID:12057765.

Duke, J.A., (1992): Handbook of Phytochemical Constituents of GRAS Herbs and Other Economical Plants. CRC Press, Boca Raton, FL.

Farombi, E.O., Surh, Y.J., (2006): Heme oxygenase-1 as a potential therapeutic target for hepatoprotection. J Biochem Mol Biol 39, 479-491. PMID:17002867.

Felver, M.E., Mezey, E., McGuire, M., Mitchell, M.C., Herlong, H.F., Veech, G.A., Veech, R.L., (1990): Plasma tumor necrosis factor alpha predicts decreased long-term survival in severe alcoholic hepatitis. Alcohol Clin Exp Res 14, 255-259. PMID:2190492.

Gardner, C.R., Laskin, J.D., Dambach, D.M., Sacco, M., Durham, S.K., Bruno, M.K., Cohen, S.D., Gordon, M.K., Gerecke, D.R., Zhou, P., Laskin, D.L., (2002): Reduced hepatotoxicity of acetaminophen in mice lacking inducible nitric oxide synthase: potential role of tumor necrosis factor-alpha and interleukin-10. Toxicol Appl Pharmacol 184, 27-36. PMID:12392966.

Girish, C., Koner, B.C., Jayanthi, S., Ramachandra Rao, K., Rajesh, B., Pradhan, S.C., (2009): Hepatoprotective activity of picroliv, curcumin and ellagic acid compared to silymarin on paracetamol induced liver toxicity in mice. Fundam Clin Pharmacol 23, 735-745. PMID:19656205.

Heard, K.J., (2008): Acetylcysteine for acetaminophen poisoning. N Engl J Med 359, 285-292. PMID:18635433.

Ishida, Y., Kondo, T., Kimura, A., Tsuneyama, K., Takayasu, T., Mukaida, N., (2006): Opposite roles of neutrophils and macrophages in the pathogenesis of acetaminophen-induced acute liver injury. Eur J Immunol 36, 1028-1038. PMID:16552707.

Jaeschke, H., Bajt, M.L., (2006): Intracellular signaling mechanisms of acetaminophen-induced liver cell death. Toxicol Sci 89, 31-41. PMID:16177235. 
Jaeschke, H., Williams, C.D., Ramachandran, A., Bajt, M.L., (2011): Acetaminophen hepatotoxicity and repair: the role of sterile inflammation and innate immunity. Liver Int 32, 8-20. PMID:21745276.

James, L.P., Mayeux, P.R., Hinson, J.A., (2003): Acetaminophen-induced hepatotoxicity. Drug Metab Dispos 31, 1499-1506. PMID:14625346.

Janbaz, K.H., Saeed, S.A., Gilani, A.H., (2004): Studies on the protective effects of caffeic acid and quercetin on chemical-induced hepatotoxicity in rodents. Phytomedicine 11, 424-430. PMID:15330498.

Jayanthi, R., Subash, P., (2010): Antioxidant effect of caffeic Acid on oxytetracycline induced lipid peroxidation in albino rats. Indian $\mathrm{J}$ Clin Biochem 25, 371-375. PMID:21966107.

Jonas, J.C., Guiot, Y., Rahier, J., Henquin, J.C., (2003): Haeme-oxygenase 1 expression in rat pancreatic beta cells is stimulated by supraphysiological glucose concentrations and by cyclic AMP. Diabetologia 46, 1234-1244. PMID:12898011.

Kimata, M., Inagaki, N., Nagai, H., (2000): Effects of luteolin and other flavonoids on IgEmediated allergic reactions. Planta Med 66, 25-29. PMID:10705729.

Kus, I., Colakoglu, N., Pekmez, H., Seckin, D., Ogeturk, M., Sarsilmaz, M., (2004): Protective effects of caffeic acid phenethyl ester (CAPE) on carbon tetrachloride-induced hepatotoxicity in rats. Acta Histochem 106, 289-297. PMID:15350811.

Landar, A., Zmijewski, J.W., Dickinson, D.A., Le Goffe, C., Johnson, M.S., Milne, G.L., Zanoni, G., Vidari, G., Morrow, J.D., Darley-Usmar, V.M., (2006): Interaction of electrophilic lipid oxidation products with mitochondria in endothelial cells and formation of reactive oxygen species. Am J Physiol Heart Circ Physiol 290, H17771787. PMID:16387790.

Larson, A.M., Polson, J., Fontana, R.J., Davern, T.J., Lalani, E., Hynan, L.S., Reisch, J.S., Schiodt, F.V., Ostapowicz, G., Shakil, A.O., Lee, W.M., (2005): Acetaminopheninduced acute liver failure: results of a United States multicenter, prospective study. Hepatology 42, 1364-1372. PMID:16317692.

Lau, D., Mollnau, H., Eiserich, J.P., Freeman, B.A., Daiber, A., Gehling, U.M., Brummer, J., Rudolph, V., Munzel, T., Heitzer, T., Meinertz, T., Baldus, S., (2005): Myeloperoxidase mediates neutrophil activation by association with CD11b/CD18 integrins. Proc Natl Acad Sci U S A 102, 431-436. PMID:15625114.

Lieber, C.S., (2004): New concepts of the pathogenesis of alcoholic liver disease lead to novel treatments. Curr Gastroenterol Rep 6, 60-65. PMID:14720455.

Lieber, C.S., Leo, M.A., Cao, Q., Ren, C., DeCarli, L.M., (2003): Silymarin retards the progression of alcohol-induced hepatic fibrosis in baboons. J Clin Gastroenterol 37, 336-339. PMID:14506392.

Maddrey, W.C., (2005): Drug-induced hepatotoxicity: 2005. J Clin Gastroenterol 39, S83-89. PMID:15758665.

Mitchell, J.R., Jollow, D.J., Potter, W.Z., Gillette, J.R., Brodie, B.B., (1973): Acetaminopheninduced hepatic necrosis. IV. Protective role of glutathione. J Pharmacol Exp Ther 187, 211-217. PMID:4746329. 
Mohri, T., Ogura, H., Koh, T., Fujita, K., Sumi, Y., Yoshiya, K., Matsushima, A., Hosotsubo, H., Kuwagata, Y., Tanaka, H., Shimazu, T., Sugimoto, H., (2006): Enhanced expression of intracellular heme oxygenase- 1 in deactivated monocytes from patients with severe systemic inflammatory response syndrome. J Trauma 61, 616-623; discussion 623. PMID:16966997.

Moreira, A.S., Spitzer, V., Schapoval, E.E., Schenkel, E.P., (2000): Antiinflammatory activity of extracts and fractions from the leaves of Gochnatia polymorpha. Phytother Res 14, 638-640. PMID:11114003.

Morris, S.M., Jr., Billiar, T.R., (1994): New insights into the regulation of inducible nitric oxide synthesis. Am J Physiol 266, E829-839. PMID:8023911.

Muriel, P., (2009): NF-kappaB in liver diseases: a target for drug therapy. J Appl Toxicol 29, 91-100. PMID:18937212.

Nagi, M.N., Almakki, H.A., Sayed-Ahmed, M.M., Al-Bekairi, A.M., (2010): Thymoquinone supplementation reverses acetaminophen-induced oxidative stress, nitric oxide production and energy decline in mice liver. Food Chem Toxicol 48, 2361-2365. PMID:20561950.

Nakahira, K., Takahashi, T., Shimizu, H., Maeshima, K., Uehara, K., Fujii, H., Nakatsuka, H., Yokoyama, M., Akagi, R., Morita, K., (2003): Protective role of heme oxygenase-1 induction in carbon tetrachloride-induced hepatotoxicity. Biochem Pharmacol 66, 1091-1105. PMID:12963497.

Nassar, I., Pasupati, T., Judson, J.P., Segarra, I., (2009): Reduced exposure of imatinib after coadministration with acetaminophen in mice. Indian J Pharmacol 41, 167-172. PMID:20523867.

Ndisang, J.F., (2010): Role of heme oxygenase in inflammation, insulin-signalling, diabetes and obesity. Mediators Inflamm 2010, 359732. PMID:20508722.

Ndisang, J.F., Jadhav, A., (2009): Upregulating the heme oxygenase system suppresses left ventricular hypertrophy in adult spontaneously hypertensive rats for 3 months. J Card Fail 15, 616-628. PMID:19700139.

Ndisang, J.F., Tabien, H.E., Wang, R., (2004): Carbon monoxide and hypertension. J Hypertens 22, 1057-1074. PMID:15167436.

Ndisang, J.F., Wu, L., Zhao, W., Wang, R., (2003): Induction of heme oxygenase-1 and stimulation of cGMP production by hemin in aortic tissues from hypertensive rats. Blood 101, 3893-3900. PMID:12506017.

Nelson, S.D., (1995): Mechanisms of the formation and disposition of reactive metabolites that can cause acute liver injury. Drug Metab Rev 27, 147-177. PMID:7641574.

Nishikimi, M., Appaji, N., Yagi, K., (1972): The occurrence of superoxide anion in the reaction of reduced phenazine methosulfate and molecular oxygen. Biochem Biophys Res Commun 46, 849-854. PMID:4400444.

Ohkawa, H., Ohishi, N., Yagi, K., (1979): Assay for lipid peroxides in animal tissues by thiobarbituric acid reaction. Anal Biochem 95, 351-358. PMID:36810. 
Oz, H.S., Chen, T.S., (2008): Green-tea polyphenols downregulate cyclooxygenase and Bcl-2 activity in acetaminophen-induced hepatotoxicity. Dig Dis Sci 53, 2980-2988. PMID:18373199.

Pestka, S., Krause, C.D., Walter, M.R., (2004): Interferons, interferon-like cytokines, and their receptors. Immunol Rev 202, 8-32. PMID:15546383.

Rice-Evans, C.A., Miller, N.J., (1996): Antioxidant activities of flavonoids as bioactive components of food. Biochem Soc Trans 24, 790-795. PMID:8878849.

Russo, M., Palumbo, R., Tedesco, I., Mazzarella, G., Russo, P., Iacomino, G., Russo, G.L., (1999): Quercetin and anti-CD95(Fas/Apo1) enhance apoptosis in HPB-ALL cell line. FEBS Lett 462, 322-328. PMID:10622719.

Ryder, S.D., Beckingham, I.J., (2001): ABC of diseases of liver, pancreas, and biliary system. Other causes of parenchymal liver disease. Bmj 322, 290-292. PMID:11157536.

Ryter, S.W., Kim, H.P., Nakahira, K., Zuckerbraun, B.S., Morse, D., Choi, A.M., (2007): Protective functions of heme oxygenase- 1 and carbon monoxide in the respiratory system. Antioxid Redox Signal 9, 2157-2173. PMID:17845132.

Scapagnini, G., Foresti, R., Calabrese, V., Giuffrida Stella, A.M., Green, C.J., Motterlini, R., (2002): Caffeic acid phenethyl ester and curcumin: a novel class of heme oxygenase1 inducers. Mol Pharmacol 61, 554-561. PMID:11854435.

Schumann, J., Prockl, J., Kiemer, A.K., Vollmar, A.M., Bang, R., Tiegs, G., (2003): Silibinin protects mice from $T$ cell-dependent liver injury. $J$ Hepatol 39, 333-340. PMID:12927918.

Sener, G., Toklu, H.Z., Sehirli, A.O., Velioglu-Ogunc, A., Cetinel, S., Gedik, N., (2006): Protective effects of resveratrol against acetaminophen-induced toxicity in mice. Hepatol Res 35, 62-68. PMID:16595188.

Soleas, G.J., Grass, L., Josephy, P.D., Goldberg, D.M., Diamandis, E.P., (2002): A comparison of the anticarcinogenic properties of four red wine polyphenols. Clin Biochem 35, 119-124. PMID:11983346.

Song, Z., Deaciuc, I., Song, M., Lee, D.Y., Liu, Y., Ji, X., McClain, C., (2006): Silymarin protects against acute ethanol-induced hepatotoxicity in mice. Alcohol Clin Exp Res 30, 407-413. PMID:16499481.

Tanaka, J., Yuda, Y., Yamakawa, T., (2001): Mechanism of superoxide generation system in indomethacin-induced gastric mucosal injury in rats. Biol Pharm Bull 24, 155-158. PMID:11217083.

Teng, C.Y., Lai, Y.L., Huang, H.I., Hsu, W.H., Yang, C.C., Kuo, W.H., (2012): Tournefortia sarmentosa extract attenuates acetaminophen-induced hepatotoxicity. Pharm Biol 50, 291-396. PMID:22085220.

Williams, R.J., Spencer, J.P., Rice-Evans, C., (2004): Flavonoids: antioxidants or signalling molecules? Free Radic Biol Med 36, 838-849. PMID:15019969.

Yan, S.L., Wu, S.T., Yin, M.C., Chen, H.T., Chen, H.C., (2009): Protective effects from carnosine and histidine on acetaminophen-induced liver injury. J Food Sci 74, H259265. PMID:19799668. 
Yoo, H.G., Jung, S.N., Hwang, Y.S., Park, J.S., Kim, M.H., Jeong, M., Ahn, S.J., Ahn, B.W., Shin, B.A., Park, R.K., Jung, Y.D., (2004): Involvement of NF-kappaB and caspases in silibinin-induced apoptosis of endothelial cells. Int J Mol Med 13, 81-86. PMID: 14654975 .

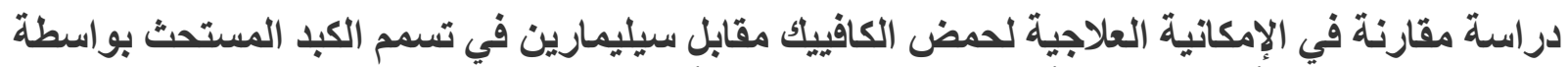

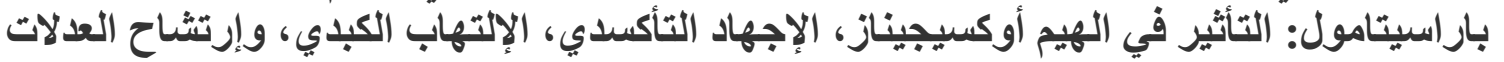

$$
\text { منى فرج العزب* }
$$

قسم الأدويةو السموم ، كلية الصيدلة ، جامعة قناة السويس

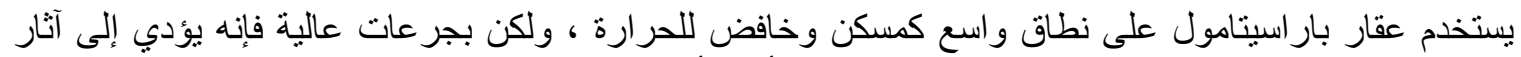

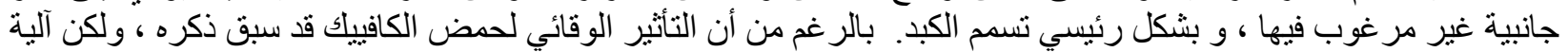

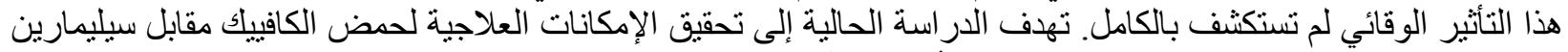

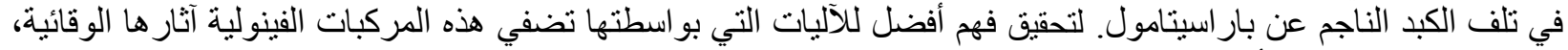

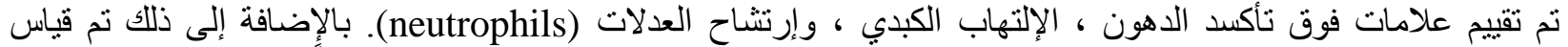

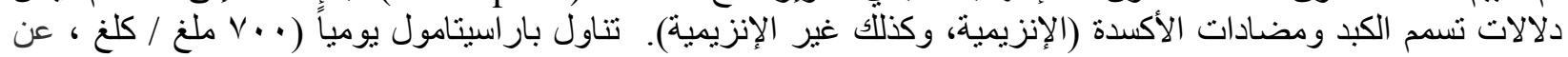

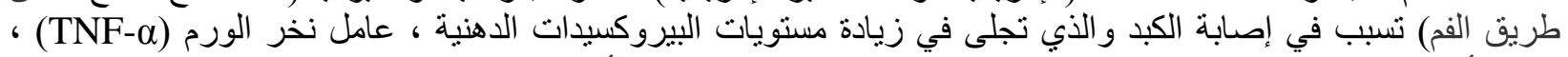

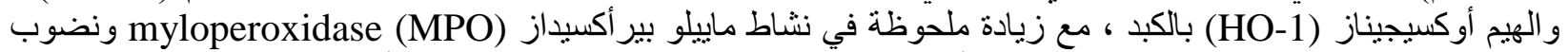

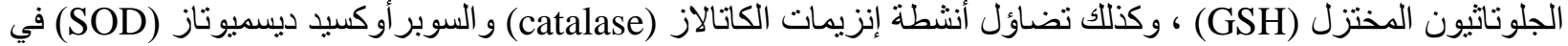

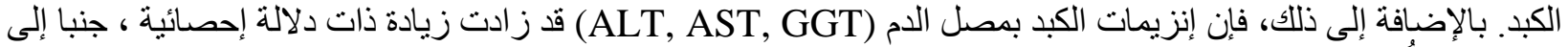

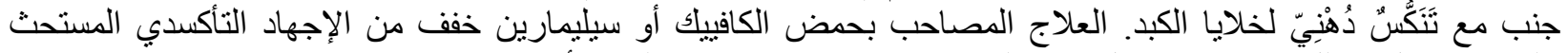
بالبار اسيتامول ، قلل مستويات عامل نخر الورم (TNF-

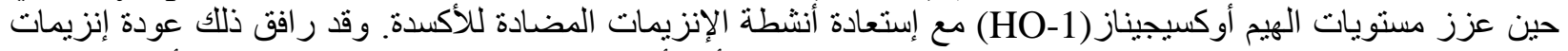

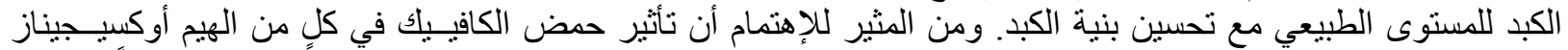

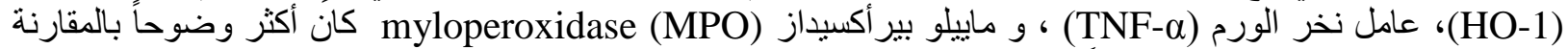

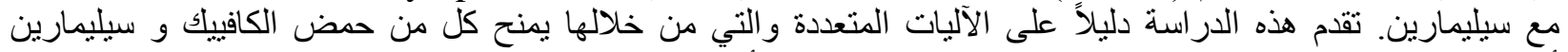

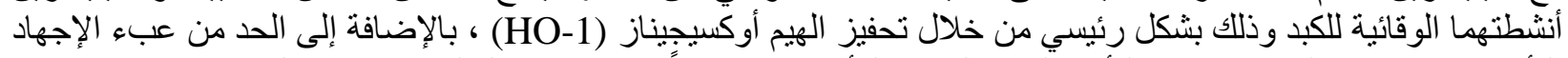

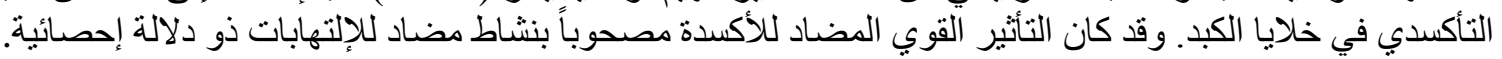

